\title{
Some Classes of Generalized Entire Sequences of Fuzzy Number
}

\author{
A.Padiarani \\ Department of Mathematics, G.Venkata Swamy Naidu College, Kovilpatti-628502, Tamil Nadu, India.
}

\begin{abstract}
The object of the present paper is to introduce the sequence spaces $\lambda_{o}(M, \phi, P)$ defined by the sequence of fuzzy numbers and $p=\left(p_{k}\right)$ be any bounded sequence of positive real numbers. We study their different algebraic and topological properties. We also obtain some inclusion relations between these spaces.
\end{abstract}

Keywords and phrases: Fuzzy number, entire sequence spaces, completeness, convergence, boundedness. This work is supported by UGC MRP(5647)

\section{Introduction}

The concept of fuzzy set theory was introduced by zadeh [14 ] and subsequently several authors have discussed various aspects of the theory and applications of fuzzy sets such as fuzzy topological spaces, similarity relations and fuzzy orderings, fuzzy measures of fuzzy events, fuzzy mathematical programming. Matloka [7] introduced bounded and convergent sequences of fuzzy numbers and studied some of their properties. Later on sequences of fuzzy numbers have been discussed by Nanda [9] savas [12], Mursaleen [ 8 ], Thripathy[13 ] and Dutta [2] and many others. Ganapathy Iyer [1 ] studied the space of all entire functions. Maddox [5] generalised the space of all entire functions as a special class of sequences of complex numbers $\mathrm{c}_{\mathrm{o}}(\mathrm{P})$.

Let $\mathrm{p}=\left(\mathrm{p}_{\mathrm{k}}\right)$ be any sequences of strictly positive real numbers. The class of sequences defined by Maddox [6] was

$$
\mathrm{c}_{\mathrm{o}}(\mathrm{p})=\left\{\mathrm{x} \in \omega:\left|x_{k}\right|^{p_{k}} \rightarrow o\right\}
$$

2000 Mathematics subject classification 46A45

When all the terms of $\left(p_{k}\right)$ are constants and all equal to $p>o$ we have $c_{o}(p)=c_{o}$, the space all null sequences. The special FK - space $c_{o}(1 / k)$ was studied by Ganapathy Iyer [ 1] who indentified it with the space of all entire functions.

Kampthan [3] studied the class,

$$
\mathrm{X}=\left\{f: f(z)=\sum a_{n} z^{n},\left|n ! a_{n}\right|^{1 / n} \rightarrow o \text { as } n \rightarrow \infty\right\} \text { consisting of all entire functions of order } 1
$$

and type $\mathrm{o}$ and showed that $\mathrm{X}$ is a Frechet space with the total paranorm

$$
\|\mathrm{f}\|=\sup \left\{\left|n ! a_{n}\right|^{1 / n},(n \geq 1)\right\}
$$

Recently Nuray and Savas [ ] have defined the following space of sequences of fuzzy numbers

$$
l(\mathrm{p})=\left\{x=\left(x_{k}\right): \sum_{k}\left[\bar{d}\left(x_{k}, \bar{o}\right)\right]^{P_{k}}<\infty\right\}
$$

where $\left(p_{k}\right)$ is a bounded sequence of strictly positive real numbers. Mursaleen and Metin Basarir [8] studied the spaces $\mathrm{F}_{\mathrm{o}}(\mathrm{p}), \mathrm{F}_{\infty}(\mathrm{p})$ and $\mathrm{F}(\mathrm{p})$.

Our aim is to introduce the space $\lambda_{0}(\mathrm{M}, \phi, \mathrm{p})$. We establish the condition for $\lambda_{\mathrm{o}}(\mathrm{M}, \phi, \mathrm{P})$ to be identical with $\mathrm{c}_{\mathrm{o}}(\mathrm{M}, \phi, \mathrm{P})$. Also we give the necessary and sufficient condition for $\lambda_{\mathrm{o}}(\mathrm{M}, \phi, \mathrm{P})$ to be included in $\mu_{\mathrm{o}}(\mathrm{M}, \phi, \mathrm{P})$.

\section{Definitions and Preliminaries}

We begin with giving some required definitions and statements of theorems, propositions and lemmas. A fuzzy number is a fuzzy set on the real axis i.e. a mapping $\mathrm{u}: \mathrm{R} \rightarrow[0,1]$ which satisfies the following four conditions.

(i) $\mathrm{u}$ is normal i.e. there exists an $\mathrm{x}_{0} \in \mathrm{R}$ such that $\mathrm{u}\left(\mathrm{x}_{0}\right)=1$

ii) $u$ is fuzzy convex i.e. $u[\lambda x+(1-\lambda) y] \geq \min \{u(x), u(y)\}$ for all $x, y \in R$ and for all $\lambda \in[0,1]$

iii) $\mathrm{u}$ is upper semi continuous

iv) The set $[\mathrm{u}]_{0}=\{\overline{x \in R: u(x)>0}\} \quad$ is compact (Zadeh [14] ) where $\{\overline{x \in R: u(x)>0}\}$ denotes the closure of the set $\{x \in R: u(t)>0\}$ in the usual topology of R. We denote the set of all fuzzy numbers on $\mathrm{R}$ 
by $\mathrm{E}^{\prime}$ and called it as the space of fuzzy numbers. The $\lambda$-level set $[\mathrm{u}]_{\lambda}$ of $\mathrm{u} \in \mathrm{E}^{\prime}$ is defined by

$$
[u]_{\lambda}=\left\{\begin{array}{lc}
\{t \in R: u(t) \geq \lambda\}, & (0<\lambda \leq 1) \\
\{t \in R: u(t)>\lambda\}, & \lambda=0
\end{array}\right.
$$

The set $[\mathrm{u}]_{\lambda}$ is a closed bounded and non-empty interval for each $\lambda \in[0,1]$ which is defined by

$$
[\mathrm{u}]_{\lambda}=\left[\mathrm{u}^{-}(\lambda), \mathrm{u}^{+}(\lambda)\right]
$$

$\mathbb{R}$ can be embedded in $\mathrm{E}^{\prime}$. Since each $\mathrm{r} \in \mathbb{R}$ can be regarded as a fuzzy number $\bar{r}$ defined by

$$
\bar{r}(x)= \begin{cases}1, & (x=r) \\ 0, & (x \neq r)\end{cases}
$$

Let $\mathrm{u}, \mathrm{v}, \mathrm{w} \in \mathrm{E}^{\prime}$ and $\mathrm{k} \in \mathbb{R}$. The operations addition, scalar multiplication and product defined on $\mathrm{E}^{\prime}$ by

$\mathrm{u}+\mathrm{v}=\mathrm{w} \Leftrightarrow[\mathrm{w}]_{\lambda}=[\mathrm{u}]_{\lambda}+[\mathrm{v}]_{\lambda}$ for all $\lambda \in[0,1]$

$$
\Leftrightarrow w^{-}(\lambda)=\left[u^{-}(\lambda), v^{-}(\lambda)\right] \text { and } w^{+}(\lambda)=\left[u^{+}(\lambda), v^{+}(\lambda)\right] \text { and for all } \lambda \in[0,1]
$$

and

$[\mathrm{ku}]_{\lambda}=\mathrm{k}[\mathrm{u}]_{\lambda}$ for all $\lambda \in[0,1]$

$\mathrm{uv}=\mathrm{w} \Leftrightarrow[\mathrm{w}]_{\lambda}=[\mathrm{u}]_{\lambda}[\mathrm{v}]_{\lambda}$ for all $\lambda \in[0,1]$

where it is immediate that ,

$$
w^{-}(\lambda)=\min \left\{u^{-}(\lambda) v^{-}(\lambda), u^{-}(\lambda) v^{+}(\lambda), \quad u^{+}(\lambda) v^{-}(\lambda), \quad u^{+}(\lambda) v^{+}(\lambda)\right\}
$$

and

$$
w^{+}(\lambda)=\max \left\{u^{-}(\lambda) v^{-}(\lambda), \quad u^{-}(\lambda) v^{+}(\lambda), \quad u^{+}(\lambda) v^{-}(\lambda), \quad u^{+}(\lambda) v^{+}(\lambda)\right\}
$$

for all $\lambda \in[0,1]$.

$$
\begin{aligned}
u / v=w \Leftrightarrow[w]_{\alpha}=[\mathrm{u}]_{\alpha} /[\mathrm{v}]_{\alpha} \text { for all } \alpha \in[0,1] \\
=\left[\mathrm{u}^{-}(\alpha), \mathrm{u}^{+}(\alpha)\right] \cdot\left[\frac{1}{v^{-}(\alpha)}, \frac{1}{v^{+}(\alpha)}\right] \\
=\left[\min \left\{\frac{[\mathrm{u}]^{-}(\alpha)}{[\mathrm{v}]^{+}(\alpha)}, \frac{u^{-}(\alpha)}{v^{-}(\alpha)}, \frac{u^{+}(\alpha)}{v^{+}(\alpha)}, \frac{u^{+}(\alpha)}{v^{-}(\alpha)}\right\}, \operatorname{Max}\left\{\frac{[\mathrm{u}]^{-} \alpha}{[\mathrm{v}]^{+} \alpha}, \frac{u^{-}(\alpha)}{v^{-}(\alpha)}, \frac{u^{+}(\alpha)}{v^{+}(\alpha)}, \frac{u^{+}(\alpha)}{v^{-}(\alpha)}\right\}\right]
\end{aligned}
$$

Let $\mathrm{W}$ be the set of all closed and bounded intervals $\mathrm{A}$ of real numbers with endpoints $\underline{A}$ and $\bar{A}$ ie) $\mathrm{A}=[\underline{A}, \bar{A}]$

Define the relation $\mathrm{d}$ on $\mathrm{W}$ by

$\mathrm{d}(\mathrm{A}, \mathrm{B})=\max \{|\underline{A}-\underline{B}|,|\bar{A}-\bar{B}|\}$

Then it can be observed that $\mathrm{d}$ is a metric on $\mathrm{W}$ and $(\mathrm{W}, \mathrm{d}$ ) is a complete metric space (Nanda [9]) . Now we can define the metric $\mathrm{D}$ on $\mathrm{E}^{\prime}$ by means of a Hausdroff metric $\mathrm{d}$ as

$\mathrm{D}(\mathrm{u}, \mathrm{v})=\sup \mathrm{d}\left([\mathrm{u}]_{\lambda,},[\mathrm{v}]_{\lambda}\right)=\sup _{\lambda \in[0,1]} \max \left\{\left|\mathrm{u}^{-}(\lambda)-\mathrm{v}^{-}(\lambda)\right|,\left|\mathrm{u}^{+}(\lambda)-\mathrm{v}^{+}(\lambda)\right|\right\}$

$\left(\mathrm{E}^{\prime}, \mathrm{D}\right)$ is a complete metric space .One can extend the natural order relation on the real line to intervals as follows .

$\mathrm{A} \leq \mathrm{B}$ if and only if $\underline{A} \leq \underline{B}$ and $\bar{A} \leq \bar{B}$

The partial order relation on $\mathrm{E}^{\prime}$ is defined as follows.

$$
\mathrm{u} \leq \mathrm{v} \Leftrightarrow[u]_{\lambda} \leq[v]_{\lambda} \Leftrightarrow u^{-}(\lambda) \leq v^{-}(\lambda) \text { and } u^{+}(\lambda) \leq v^{+}(\lambda) \text { for all } \lambda \in[0,1]
$$

An absolute value $|\mathrm{u}|$ of a fuzzy number $\mathrm{u}$ is defined by

$$
|u|(t)=\left\{\begin{array}{cc}
\max \{u(t), u(-t)\}, & (t \geq 0) \\
0, & (t<0)
\end{array}\right.
$$

$\lambda$-level set $[|u|]_{\lambda}$ of the absolute value of $\mathbf{u} \in \mathrm{E}^{\prime}$ is in the form $[|u|]_{\lambda}$

where

$$
\begin{aligned}
|u|^{-}(\lambda) & =\max \left\{0, u^{-}(\lambda),-u^{+}(\lambda)\right\} \\
\left.|u|^{+}(\lambda)\right) & =\max \left\{\left|u^{-}(\lambda)\right|,\left|u^{+}(\lambda)\right|\right\}
\end{aligned}
$$

The absolute value $|\mathrm{uv}|$ of $\mathrm{u}, \mathrm{v} \in \mathrm{E}^{\prime} \quad$ satisfies the inequalities (Talo [8]) 
$|u v|^{-}(\lambda) \leq|u v|^{+}(\lambda) \leq \max \left\{\left|u^{-}(\lambda)\right|\left|v^{-}(\lambda)\right|, \quad\left|u^{-}(\lambda)\right|\left|v^{+}(\lambda)\right|, \quad\left|u^{+}(\lambda)\right|\left|v^{-}(\lambda)\right|, \quad\left|u^{+}(\lambda)\right|\left|v^{+}(\lambda)\right|\right\}$

$\mathrm{u} \in \mathrm{E}^{\prime}$ is a non-negative fuzzy number if and only if $\mathrm{u}(\mathrm{x})=0$ for all $\mathrm{x}<0$. It is immediate that $\mathrm{u} \geq 0$ if $\mathrm{u}$ is a non negative fuzzy number.

One can see that

$$
\mathrm{D}(\mathrm{u}, \overline{0})=\sup \max _{\lambda \in[0,1]}\left\{\left|\mathrm{u}^{-}(\lambda)\right|,\left|\mathrm{u}^{+}(\lambda)\right|\right\}=\max \left\{\left|\mathrm{u}^{-}(\lambda)\right|,\left|\mathrm{u}^{+}(\lambda)\right|\right\} \text {. }
$$

Proposition 2.1 Let $\mathrm{u}, \mathrm{v}, \mathrm{w} \in \mathrm{E}^{\prime}$ and $\mathrm{k} \in \mathrm{R}$. Then

(i) $\left(\mathrm{E}^{\prime}, \mathrm{D}\right)$ Is a complete Metric space

(ii) $\mathrm{D}(\mathrm{ku}, \mathrm{kv})=|\mathrm{k}| \mathrm{D}(\mathrm{u}, \mathrm{v})$

(iii) $\mathrm{D}(\mathrm{u}+\mathrm{v}, \mathrm{w}+\mathrm{v})=\mathrm{D}(\mathrm{u}, \mathrm{w})$

(iv) $\mathrm{D}(\mathrm{u}+\mathrm{v}, \mathrm{w}+\mathrm{z}) \leq \mathrm{D}(\mathrm{u}, \mathrm{w})+\mathrm{D}(\mathrm{v}, \mathrm{z})$

(v) $|\mathrm{D}(\mathrm{u}, \overline{0})-\mathrm{D}(\mathrm{v}, \overline{0})| \leq \mathrm{D}(\mathrm{u}, \mathrm{v}) \leq \mathrm{D}(\mathrm{u}, \overline{0})+\mathrm{D}(\mathrm{v}, \overline{0})$.

Lemma 2.2 The following statements hold (Talo [11])

(i) $D(u v, \overline{0}) \leq D(u, \overline{0}) D(v, \overline{0}) \quad$ for all $\mathrm{u}, \mathrm{v} \in \mathrm{E}^{\prime}$

(ii) If $\mathrm{u}_{\mathrm{k}} \rightarrow \mathrm{u}$ as $\mathrm{k} \rightarrow \infty$ then $\mathrm{D}\left(\mathrm{u}_{\mathrm{k}}, \overline{0}\right) \rightarrow \mathrm{D}(\mathrm{u}, 0)$ as $\mathrm{k} \rightarrow \infty$ where $\left(\mathrm{u}_{\mathrm{k}}\right) \in \mathrm{w}(\mathrm{F})$.

In the sequel, we require the following Definitions and lemmas.

Definition: 2.3 A sequence $\mathrm{u}=\left(\mathrm{u}_{\mathrm{k}}\right)$ of fuzzy numbers is a function $\mathrm{u}$ from the set $\mathrm{N}$ into the set $\mathrm{E}^{\prime}$. The fuzzy number $u_{k}$ denotes the value of the function at $k \in \mathbb{N}$ and is called the $k^{\text {th }}$ term of the sequence. Let $w(F)$ denote the set of all sequences of fuzzy numbers.

Definition : 2.4 A sequence $\left(u_{k}\right) \in w(F)$ is called convergent with limit $u \in E^{\prime}$ if and only if for every $\varepsilon>0$ there exists an $\mathrm{n}_{0}=\mathrm{n}_{0}(\varepsilon) \in \mathrm{N}$ such that $\mathrm{D}\left(\mathrm{u}_{\mathrm{k}}, \mathrm{u}\right)<\varepsilon$ for all $\mathrm{k} \geq \mathrm{n}_{0}$.

Theorem 2.5 [7]. Let $\left(\mathrm{u}_{\mathrm{k}}\right),\left(\mathrm{v}_{\mathrm{k}}\right) \in \mathrm{w}(\mathrm{F})$ with $\mathrm{u}_{\mathrm{k}} \rightarrow \mathrm{a}, \mathrm{v}_{\mathrm{k}} \rightarrow \mathrm{b}$ as $\mathrm{k} \rightarrow \infty$.Then,

i. $\mathrm{u}_{\mathrm{k}}+\mathrm{v}_{\mathrm{k}} \rightarrow \mathrm{a}+\mathrm{b}$ as $\mathrm{k} \rightarrow \infty$

ii. $\mathrm{u}_{\mathrm{k}}-\mathrm{v}_{\mathrm{k}} \rightarrow \mathrm{a}-\mathrm{b}$ as $\mathrm{k} \rightarrow \infty$

iii. $\mathrm{u}_{\mathrm{k}} \mathrm{v}_{\mathrm{k}} \rightarrow \mathrm{ab}$ as $\mathrm{k} \rightarrow \infty$

iv. $u_{k} u_{k} / v_{k} \rightarrow a / b$ as $k \rightarrow \infty$ where $0 \notin\left[v_{k}\right]_{0}$ for all $k \in N$ and $0 \notin[b]_{0}$.

Definition : 2.6 A sequence $\left(u_{k}\right) \in w(F)$ is called bounded if and only if the set of all fuzzy numbers consisting of the terms of the sequence $\left(\mathrm{u}_{\mathrm{k}}\right)$ is a bounded set.

That is to say that a sequences $\left(\mathrm{u}_{\mathrm{k}}\right) \in \mathrm{w}(\mathrm{F})$ is said to be bounded if and only if there exist two fuzzy numbers $\mathrm{m}$ and $\mathrm{M}$ such that $\mathrm{m} \leq \mathrm{u}_{\mathrm{k}} \leq \mathrm{M}$ for all $\mathrm{k} \in \mathrm{N}$.

\section{The space $\lambda_{0}(\mathbf{M}, \phi, p)$}

Let $\Lambda=\left(\lambda_{\mathrm{k}}\right)$ be a sequence of non-zero fuzzy numbers and let $\mathrm{u}=\left(\mathrm{u}_{\mathrm{k}}\right)$ be any sequence of fuzzy numbers. Put $\Lambda \mathrm{u}=\left(\lambda_{\mathrm{k}} \mathrm{u}_{\mathrm{k}}\right)$ and $(\Lambda \mathrm{u})_{\mathrm{k}}=\lambda_{\mathrm{k}} \mathrm{u}_{\mathrm{k}}$.

Then define.

$$
\lambda_{\mathrm{o}}(\mathrm{M}, \phi, \mathrm{p})=\left\{u=\left(u_{k}\right) \in c_{o}(F): \sup _{s \geq 1} \sup _{\alpha \in c_{s}} 1 \lim D\left[(\Lambda u)_{k}, \bar{o}\right]=o\right\}
$$

Theorem 3.1. $\lambda_{0}(\mathrm{M}, \phi, \mathrm{p})$ is a complete metric space if and only if

$$
\lim _{k \rightarrow \infty} \inf \left\{D\left(\lambda_{k}, \bar{o}\right)\right\}>o
$$

Proof. The Metric on $\lambda_{0}(F)$ is given by

$$
\begin{aligned}
\mathrm{d}_{\mathrm{o}}(\mathrm{u}, \mathrm{v}) & =\sup _{k} D\left[(\Lambda u)_{k},(\Lambda v)_{k}\right]= \\
\sup & \sup _{\alpha \in[0,1]} \max \left\{\left|\left(\lambda_{k} u_{k}\right)^{-}(\alpha)-\left(\lambda_{k} v_{k}\right)^{-}(\alpha)\right|,\left|\left(\lambda_{k} u_{k}\right)^{+}(\alpha)-\left(\lambda_{k} v_{k}\right)^{+}(\alpha)\right|\right\}
\end{aligned}
$$

Let $\left\{\mathrm{u}^{(\mathrm{i})}\right\}$ be any Cauchy sequence in $\lambda_{0}(\mathrm{~F})$.

Then given $\varepsilon>0$ there exists a positive integer no such that 


$$
\sup _{k} D\left[\left(\Lambda u^{(i)}\right)_{k},\left(\Lambda u^{(i)}\right)_{k}\right]<\varepsilon
$$

for all $i, j \geq n_{o}$ and for all $k$

i.e. $\sup _{k} \sup _{\alpha \in[0,1]} \max \left\{\left|\left(\lambda_{k} u_{k}^{i}\right)^{-}(\alpha)-\left(\lambda_{k} u_{k}^{j}\right)^{-}(\alpha)\right|,\left|\left(\lambda_{k} u_{k}^{i}\right)^{+}(\alpha)-\left(\lambda_{k} u_{k}^{j}\right)^{+}(\alpha)\right|\right\} \quad$ for all $\mathrm{i}, \mathrm{j} \geq$ $\mathrm{n}_{\mathrm{o}}$ and for all $\mathrm{k}$.

Let $\mathrm{L}=\lim \inf \left\{\mathrm{D}\left(\lambda_{k}, \bar{o}\right)\right\}$

$$
=\lim \inf \left\{\sup _{\alpha \in[0,1]} \max \left\{\left|\lambda_{k}^{-}(\alpha)\right|,\left|\lambda_{k}^{+}(\alpha)\right|\right\}\right\}
$$

Using (3.1.3) and (3.1.4)

$$
\left|\mathrm{u}_{\mathrm{k}}^{(\mathrm{i})-}(\alpha)-u_{k}^{(j)-}(\alpha)\right|<\frac{\varepsilon}{L} \text { and }\left|u_{k}^{(i)+}(\alpha)-u_{k}^{(j)+}(\alpha)\right|<\frac{\varepsilon}{L}
$$

for all $\mathrm{I}, \mathrm{j} \geq \mathrm{n}_{\mathrm{o}}$

Hence $\left\{u_{k}^{(i)}\right\}$ is a Cauchy sequence in $\mathrm{E}^{\prime}$ and since $\left(\mathrm{E}^{\prime}, \mathrm{D}\right)$ is complete

$$
\left\{u_{k}^{(i)}\right\} \rightarrow \mathrm{u}_{\mathrm{k}} \text { as } \mathrm{i} \rightarrow \infty
$$

Thus $\mathrm{D}\left(u_{k}^{(i)}, u_{k}\right)<\frac{\varepsilon}{L}$ for all $\mathrm{i}, \mathrm{j} \geq \mathrm{n}_{\mathrm{o}}$ for all $\mathrm{k}$.

Letting $\mathrm{j} \rightarrow \infty$ in (3.1.5)

Then $\quad\left|u_{k}^{(i)-}(\alpha)-u_{k}(\alpha)\right|<\frac{\varepsilon}{L}$ and $\left|u_{k}^{(i)+}(\alpha)-u_{k}(\alpha)\right|<\frac{\varepsilon}{L}$

Now

$$
\left|\lambda_{k}^{-}(\alpha)\right|\left|u_{k}^{(i)-}(\alpha)-u_{k}^{-}(\alpha)\right|<\varepsilon
$$

and

$$
\left|\lambda_{k}^{+}(\alpha)\right|\left|u_{k}^{(i)+}(\alpha)-u_{k}^{-}(\alpha)\right|<\varepsilon
$$

Hence

$$
\sup _{k} \sup _{\alpha \in[0,1]} \max \left\{\left|\lambda_{k}^{-}(\alpha)\right|\left|u_{k}^{(i)-}(\alpha)-u_{k}^{-}(\alpha)\right|,\left|\lambda_{k}^{+}(\alpha)\right|\left|u_{k}^{(i)+}(\alpha)-u_{k}^{+}(\alpha)\right|\right\}<\varepsilon
$$

Thus $u_{k}^{(i)} \rightarrow u$ in $\lambda_{\mathrm{o}}(\mathrm{F})$.

$$
\text { Since each }\left(\mathrm{u}^{\mathrm{i}}\right) \text { is in } \lambda_{\mathrm{o}}(\mathrm{F}) \text { we have } \mathrm{D}\left(u_{k}^{(i)}, \overline{0}\right)<\frac{\varepsilon}{L}
$$

Using (3.1.4) and (3.1.6)

$$
\begin{array}{ll}
\leq \quad \mathrm{D}\left[(\Lambda \mathrm{u})_{\mathrm{k}}, \overline{0}\right]= & \mathrm{D}\left[\lambda_{\mathrm{k}} \mathrm{u}_{\mathrm{k}}, \overline{0}\right] \\
& \mathrm{D}\left(\lambda_{\mathrm{k}}, \overline{0}\right) \mathrm{D}\left(\mathrm{u}_{\mathrm{k}}, \overline{0}\right) \text { (Talo [ ]) } \\
& \mathrm{L}\left(\frac{\varepsilon}{L}+\frac{\varepsilon}{L}\right)
\end{array}
$$

Hence $\mathrm{u} \in \lambda_{\mathrm{o}}(\mathrm{F})$

Thus $\lambda_{\mathrm{o}}(\mathrm{F})$ is complete.

Conversely suppose (3.1.1) is not true. Then $\left\{D\left(\lambda_{k}, \overline{0}\right)\right\}$ contains a subsequence $\left\{D\left(\lambda n_{k}, \overline{0}\right)\right\}$ which is steadily decreasing and tends to zero. Consider the sequence $\left\{u_{k}^{(n)}\right\}_{n=1}^{\infty}$ where

$$
u_{k}^{(n)}=\left\{\begin{array}{ccc}
\overline{1} & \text { if } k=k_{1}, k_{2}, k_{3}, \ldots \ldots \ldots . . . k_{n} \\
& \overline{0} \quad \text { Otherwise }
\end{array}\right.
$$

Then $u_{k}^{(n)} \in \lambda_{\mathrm{o}}(\mathrm{F})$ for all $\mathrm{n}=1,2,3, \ldots \ldots \ldots \ldots$

For $\mathrm{n}>\mathrm{m}$ we have

$$
\lambda_{o}\left(u_{k}^{(m)}, u_{k}^{(n)}\right)=\quad \sup _{k} D\left[\lambda_{n k} u_{k}^{(m)}, \lambda_{n k} u_{k}^{(n)}\right]
$$




$$
=\quad \mathrm{D}\left(\lambda_{\mathrm{k}(\mathrm{n}+1)}, \overline{0}\right) \text { Which tends to o as } \mathrm{n}, \mathrm{m} \rightarrow \infty
$$

But $\quad \lim _{n \rightarrow \infty} u_{k}^{(m)}=(\overline{1}, \overline{1}, \ldots \ldots \ldots \ldots)$

which is not in $\lambda_{0}(\mathrm{~F})$

Thus (3.1.1) must hold whenever $\lambda_{0}(\mathrm{~F})$ is complete.

\section{The space $\lambda_{0}(\mathbf{F}, \mathbf{p})$}

Throughout, let $\mathrm{p}=\left(\mathrm{p}_{\mathrm{k}}\right)$ be a bounded sequence of strictly positive real numbers and $\quad \mathrm{M}=\max \left(1\right.$, sup $\left.\mathrm{p}_{\mathrm{k}}\right)$. The space $\lambda_{0}(F, p)$ is defined as follows .

$\lambda_{0}(\mathrm{~F}, \mathrm{p})=\left\{u=\left(u_{k}\right) \in c_{o}(F, p): \lim _{n \rightarrow \infty} \sum_{k=1}^{n} D\left[(\Lambda u)_{k}, \overline{0}\right]^{p_{k}}=0\right\}$

Now $\lambda_{0}(F, p)$ is endowed with two topologies one is the metric topology $\tau$ given by metric $d$, where $\mathrm{d}(\mathrm{u}, \mathrm{v})=\sup _{k} D\left(u_{k}, v_{k}\right)^{p k / m}, \mathrm{u}, \mathrm{v} \in \lambda_{\mathrm{o}}(\mathrm{p}, \mathrm{F})$.

The metric $\mathrm{d}$ is induced by the paranorm

$$
\mathrm{g}(\mathrm{u})=\sup _{k}\left[D\left(u_{k}, \overline{0}\right)^{P_{k}}\right]^{1 / M}
$$

The other is the topology $\tau_{\lambda}$ whose metric $\mathrm{d}_{\lambda}$ is given by

$$
\mathrm{d}_{\lambda}(\mathrm{u}, \mathrm{v})=\sup _{k}\left[D\left[(\Lambda u)_{k},(\Lambda v)_{k}\right]^{P_{k}}\right]^{1 / M}, \mathrm{u}, \mathrm{v} \in \lambda_{\mathrm{o}}(\mathrm{F}, \mathrm{p})
$$

Theorem 4.1 $\quad \lambda_{0}(\mathrm{~F}, \mathrm{p}) \quad=\mathrm{c}_{0}(\mathrm{~F}, \mathrm{p})$ if and only if $\left(\lambda_{\mathrm{k}}\right) \in \ell_{\infty}(F, p)$

Proof. suppose that $\left(\lambda_{\mathrm{k}}\right) \in \ell_{\infty}(F, p)$

Then $\left(\lambda_{k} u_{k}\right) \in c_{o},(F, p)$ for every $\left(u_{k}\right) \in c_{o}(F, p)$.

Hence $c_{0}(F, P) \subset \lambda_{0}(F, P)$.Always $\lambda_{0}(F, P) \subset c_{o}(F, P)$.

Therefore $\lambda_{0}(\mathrm{~F}, \mathrm{P})=\mathrm{c}_{\mathrm{o}}(\mathrm{F}, \mathrm{P})$.

On the other hand suppose that $\lambda_{\mathrm{o}}(\mathrm{F}, \mathrm{P})=\mathrm{c}_{\mathrm{o}}(\mathrm{F}, \mathrm{P})$.

If $\left(\lambda_{k}\right) \notin \ell_{\infty}(F, P)$ then there exist a positive integer $\mathrm{r}$ such that for each $\mathrm{r}$, there exist a $\mathrm{k}(\mathrm{r})$ such that

$D\left(\lambda_{k(r)}, \overline{0}\right)>1$

Define u by

$\mathrm{u}_{\mathrm{k}}=\left\{\begin{array}{lc}\overline{1} & \text { for } k=k(r) \\ \overline{0} & \text { otherwise }\end{array}\right.$

and take $\left(\mathrm{p}_{\mathrm{k}}\right)=(1)$

Then $\mathrm{u} \in \mathrm{c}_{\mathrm{o}}(\mathrm{F}, \mathrm{P})$.

But $D(\Lambda u, \overline{0})>1$ showing that $u \notin \lambda_{o}(F, P)$.

This contradiction shows that $\left(\lambda_{\mathrm{k}}\right) \in \ell_{\infty}(F, P)$.

Corollary 4.2 $\lambda_{\mathrm{o}}(\mathrm{F})=\mathrm{c}_{\mathrm{o}}(\mathrm{F})$ if and only if $\left(\lambda_{\mathrm{k}}\right) \in \ell_{\infty}(F)$.

Theorem 4.3 In order that $\lambda_{\mathrm{o}}(\mathrm{F}, \mathrm{P}) \subset \mu_{\mathrm{o}}(\mathrm{F}, \mathrm{P})$, it is necessary and sufficient that $\min \left\{D\left(\frac{\mu_{k}}{\lambda_{k}}, \overline{0}\right)^{p_{k}}, \quad D\left(\mu_{k}, \overline{0}\right)^{p_{k}}\right\}$ is bounded.

Proof. Let A denote the set of positive integers k for which $D\left(\lambda_{k}, \overline{0}\right)^{p_{k}}>1$.

Let B denote the set of positive integer k for which $D\left(\lambda_{k}, \overline{0}\right)^{p_{k}} \leq 1$. 
If $\mathrm{k} \in \mathrm{A}$ then $\min \left\{D\left(\frac{\mu_{k}}{\lambda_{k}}, \overline{0}\right)^{p_{k}}, \quad D\left(\mu_{k}, \overline{0}\right)^{p_{k}}\right\}=D\left(\frac{\mu_{k}}{\lambda_{k}}, \overline{0}\right)^{p_{k}}$.

If $\mathrm{k} \in \mathrm{B}$ then $\left\{D\left(\frac{\mu_{k}}{\lambda_{k}}, \overline{0}\right)^{p_{k}}, D\left(\mu_{k}, \overline{0}\right)^{p_{k}}\right\}=D\left(\mu_{k}, \overline{0}\right)^{p_{k}}$.

Hence (4.3.1) is equal to the assertion that $\left\{D\left(\frac{\mu_{k}}{\lambda_{k}}, \overline{0}\right)^{p_{k}}\right\}$ is bounded for $\mathrm{k} \in \mathrm{A}$ and $\quad\left\{D\left(\mu_{k}, \overline{0}\right)^{p_{k}}\right\} \quad$ is bounded for $\mathrm{k} \in \mathrm{B}$.

Suppose (4.3.1) holds and let $\mathrm{u} \in \lambda_{\mathrm{o}}(\mathrm{F}, \mathrm{P})$.

If $\mathrm{k} \in \mathrm{A}$

Write

$$
\mathrm{u}_{\mathrm{k}} \mu_{\mathrm{k}}=\left(\mathrm{u}_{\mathrm{k}} \lambda_{\mathrm{k}}\right) \frac{\mu_{k}}{\lambda_{k}}
$$

If $\mathrm{k} \in \mathrm{B}$

In either case $\left\{D\left(u_{k} \mu_{k}, \overline{0}\right)^{p_{k}}\right\}$ is arbitrarily small for sufficiently large $\mathrm{k}$.

Hence $\lambda_{0}(\mathrm{~F}, \mathrm{P}) \subset \mu_{\mathrm{o}}(\mathrm{F}, \mathrm{P})$

On the other hand if (4.3.1) is false, we can find an increasing sequence of positive integers $\{\mathrm{k}(\mathrm{r})\}$ such that

$$
\mathrm{D}\left(\gamma_{k}, \overline{0}\right)^{P_{k(r)}} \geq r
$$

and $\mathrm{D}\left(\mu_{k(r)}, \overline{0}\right)^{P_{k(r)}} \geq r$. for $\quad \mathrm{r}=1,2,3$,

$$
\text { If } \mathrm{D}\left(\lambda_{\mathrm{k}(\mathrm{r})}, \overline{0}\right) \geq 1
$$

Define

$$
u_{k}=\left\{\begin{array}{lr}
r^{-1 / p^{k(r)}}, k=k(r), \\
0 & \text { Otherwise }
\end{array}\right. \text { ? }
$$

Then $\mathrm{D}\left(\mathrm{u}_{\mathrm{k}(\mathrm{r})} \mu_{k(r)}, \overline{0}\right)^{p_{k(r)}} \geq 1$

If D $\left(\lambda_{\mathrm{k}(\mathrm{r})}, \overline{0}\right)^{p_{k(r)}} \leq 1$

Define $\mathrm{u}_{\mathrm{k}}= \begin{cases}r^{-1 / p_{k(r)}} & k=k(r) \\ 0 & \text { Otherwise }\end{cases}$

Then $\mathrm{D}\left(u_{\mathrm{k}(\mathrm{r})}, \mu_{k(r)} \overline{0}\right)^{p_{k(r)}} \geq 1$.

Thus in either case, $\mathrm{u} \in \lambda_{0}(\mathrm{~F}, \mathrm{P})$ but $\mathrm{u} \notin \mu_{0}(\mathrm{~F}, \mathrm{P})$.

This contradicts the hypothesis that $\lambda_{\mathrm{o}}(\mathrm{F}, \mathrm{P}) \subset \mu_{0}(\mathrm{~F}, \mathrm{P})$

This completes the proof.

Corollary 4.3.3 $\lambda_{\mathrm{o}}(\mathrm{F}, \mathrm{P}) \subset \mu_{\mathrm{o}}(\mathrm{F}, \mathrm{P})$ if and only if $\min \left\{D\left(\frac{\mu_{k}}{\lambda_{k}}, \overline{0}\right) \quad D\left(\mu_{k}, \overline{0}\right)\right\} \quad$ is bounded

Theorem 4.4 $\left(\lambda_{\mathrm{o}}(\mathrm{F}, \mathrm{P}), \tau_{\lambda}\right)$ is a complete metric space if and only if

$$
\lim \inf \left\{\left[D\left(\lambda_{k}, \overline{0}\right)^{p_{k}}\right]^{1 / M}\right\} \quad<0
$$

Proof. The proof is similar to 3.1

Theorem 4.5 $\tau$ is finer than $\tau_{\lambda}$ if and only if

$$
\lim _{k \rightarrow \infty} \sup \left\{\left[D\left(\lambda_{k}, \overline{0}\right)^{p_{k}}\right]^{1 / M}\right\}<\infty
$$

Suppose that (4.5.1) holds then 
$\lim _{k \rightarrow \infty} \sup \left\{\left[D\left(\lambda_{k}, \overline{0}\right)^{p_{k}}\right]^{1 / M}\right\}=\mathrm{L}<\infty$ for some positive real numberL $>0$

That is $\lim _{k \rightarrow \infty} \sup \left\{\sup _{\alpha \in[0,1]} \max \left\{\left.\lambda_{k}^{-}(\alpha)\right|^{p_{k} / m}\left|\lambda_{k}^{+}(\alpha)\right|^{p_{k} / M}\right\}=L<\infty\right.$

Let $\in>0$ be any real number Let $\left\{\mathrm{u}^{(\mathrm{n})}\right\}$ be any sequence converging to zero in $\lambda_{0}(\mathrm{~F}, \mathrm{P})$ with respect to $\tau$.

Then there exist some $\mathrm{n}_{\mathrm{o}}$ such that $\mathrm{D}\left(u_{k}^{(n)}, \overline{0}\right)<\varepsilon / L_{\text {for all }} \mathrm{n} \geq \mathrm{n}_{\mathrm{o}}$

Consequently,

$$
\begin{aligned}
& \sup _{k}\left\{\left[D\left(u_{k}^{(n)}, \overline{0}\right)^{p_{k}}\right]^{1 / M}\right\}</ L \quad \text { for all } \mathrm{n} \geq \mathrm{n}_{\mathrm{o}} \\
& \text { ie) } \sup _{k}\left\{\sup _{\alpha \in[0,1]} \max \left\{\left(u_{k}^{(n)-}(\alpha)^{p_{k} / M}, \mid u_{k}^{(n)+}(\alpha)\right]^{p k / M}\right\}<\varepsilon / L\right.
\end{aligned}
$$

using (4.5.2) and (4.5.3)

$$
\begin{aligned}
d_{\lambda}\left(u_{k}^{(n)}, \bar{o}\right)=\sup _{k}\left[D u_{k}^{(n)}, \bar{o}^{p_{k}}\right]^{1 / M} \\
=\sup _{R}\left[D\left(\lambda_{k}, \bar{o}\right)^{p_{k}}\right]^{1 / M}\left[D\left(u_{k}^{(n)}, o\right)^{p_{k}}\right]^{1 / M} \\
<\mathrm{L} \varepsilon / L=\varepsilon \text { for all } \mathrm{n} \geq \mathrm{n}_{0}
\end{aligned}
$$

Therefore $\left\{u_{k}^{(n)}\right\}$ converges to zero with respect to $\tau$. In other words the identity map on $\left(\lambda_{0}(\mathrm{~F}, \mathrm{P}), \tau\right)$ onto $\left(\lambda_{0}(\mathrm{~F}, \mathrm{P}), \tau_{\lambda}\right)$ is continuous. Hence $\tau>\tau_{\lambda}$

Theorem 4.3.6. Let $\left(\lambda_{0}(\mathrm{~F}, \mathrm{P})\right)$ be a complete metric space and let $\mathrm{q}=\left(\mathrm{q}_{\mathrm{k}}\right)$ be a bounded sequence of strictly positive real numbers. Then the following are equivalent

i. $\quad \lambda_{0}(\mathrm{~F}, \mathrm{P}) \subset \lambda_{0}(\mathrm{~F}, \mathrm{q})$

ii. $\lim _{k \rightarrow \infty}\left(\frac{q_{k}}{p_{k}}\right)>0$

assume that (ii) is not true.

Then we can determine an increasing sequence of positive integers $\mathrm{k}(1)<\mathrm{k}(2)<$ Such that $\mathrm{q}_{\mathrm{k}(\mathrm{i})<}$ $\left(\frac{1}{i}\right) p_{k(i)}$

Define

$$
\mathrm{u}_{\mathrm{k}(\mathrm{i})}=\left\{\begin{array}{cc}
{\left[\frac{1}{i\left(D\left(\lambda_{k(i)}, \overline{0}\right)\right)^{p_{k(i)}}}\right]} & \text { for } k=k(i) \\
\overline{0} & \text { for } k \neq k(i)
\end{array}\right.
$$

Then $\mathrm{D}\left(\lambda_{\mathrm{k}(\mathrm{i})} \mathrm{u}_{\mathrm{k}(\mathrm{i})}, \overline{0}\right)^{p_{k(i)}}=\left(\frac{1}{i}\right) \rightarrow 0$ as $\mathrm{i} \rightarrow \infty$

But

$$
\text { Also } \mathrm{D}\left(\mathrm{u}_{\mathrm{k}(\mathrm{i})}, \overline{0}\right)^{p_{k(i)}} \quad \rightarrow 0 \text { as } \mathrm{i} \rightarrow \infty
$$

$$
\mathrm{D}\left(\left(\lambda_{k(i)} u_{k(i)}, \overline{0}\right)\right)^{q_{k(i)}}>\exp [-(\log i) / i \quad]>\exp \left(\frac{-1}{2}\right)
$$

This shows that $u$ does not belong to $\lambda_{\mathrm{o}}(\mathrm{F}, \mathrm{q})$ which contradicts (i) and (ii) must hold.

$$
\text { (ii) } \Rightarrow \text { (i) }
$$

Suppose (ii) holds

Then there exists $r>0$ such that $\mathrm{q}_{\mathrm{k}}>\mathrm{rp}_{\mathrm{k}}$ for all sufficiency large $\mathrm{k}$.

Therefore $\mathrm{D}\left(\lambda_{\mathrm{k}} \mathrm{u}_{\mathrm{k}}, \overline{0}\right)^{\mathrm{qk}} \leq\left[\mathrm{D}\left(\lambda_{\mathrm{k}} \mathrm{u}_{\mathrm{k}}, \overline{0}\right)^{\mathrm{pk}}\right]^{\mathrm{r}}$

Thus $\lambda_{\mathrm{o}}(\mathrm{F}, \mathrm{P}) \subset \lambda_{\mathrm{o}}(\mathrm{F}, \mathrm{q})$. 


\section{References}

[1]. Ganapathy Iyer. V, On the space of integral functions, J.Indian. Math.Soc. 12(1948) 13-30.

[2]. Hemen Dutta On the sometric spaces of $c_{o}^{F}, c^{F}$ and $\ell_{\infty}^{F}$ ActaUniversitatis Apulensis No 19(2009)107-112.

[3]. Kamthan.P.K, Bases in a certain class of Frechet space, Tamkang.J. Ma th.7(1976)41-49.

[4]. Kavi Kumar.J Azme Bin Khamis and R.Kandasamy Fuzzy entire sequence spaces International journal of mathematics and mathematical sciences 2007 article ID 58368

[5]. Maddox I.J. Elements of Functional Analysis Cambridge university press.

[6]. Maddox.I.J, Spaces of strongly summable sequences, Quart.J. Math.Oxford,(2)18(1967)345-355.

[7]. Matloka. M, Sequences of Fuzzy numbers, .BUSEFAL 28(1986) 28-37.

[8]. Mursaleen.M., M.Basarir, On some new sequence spaces of Fuzzy numbers, Indian J.Pure Appl. Math 34(9) (2003) 1351-1357.

[9]. Nandha. S, On Sequences of Fuzz numbers, Fuzzy sets and systems 33(1989) 123-126.

[10]. Nuray.F,Savas.E, Statistical convergence of sequence of fuzzy realnumbers, Math Slovaca 45(3) (1995)269-273.

[11]. Ozer Talo, Feyzi Basar Determination of the Duals of classical sets of sequences of fuzzy numbers and related matrix transformations. Computers and mathematics with applications 58(2009) 717-733.

[12]. Savas.E, A note on sequences of Fuzzy numbers Information sciences 124(2000) 297-300.

[13]. Tripathy B.C. , A class of difference sequence spaces related to the p-normed spaces $\ell^{p}$,Demonstratio Math36(4) (2003)867-872.

[14]. Zadeh L.A., Fuzzy sets, Inf. Control 8(1965) 338-353. 